\title{
Comparison of physical and chemical characteristics of collagen from the skin of cod (Gadus macrocephaius)
}

\author{
Y. Shu' ${ }^{1}$, H. Ren ${ }^{1,2}$, R. Ao ${ }^{1}$, W.C. Qi ${ }^{1}$ and Z.S. Zhang ${ }^{1}$ \\ ${ }^{1}$ College of Food Science and Technology, Agricultural University of Hebei, \\ Baoding, China \\ ${ }^{2}$ The Yaojiazhuang Town Government, Qiaodong District, Zhangjiakou, China \\ Corresponding author: Z.S. Zhang \\ E-mail: 15930431516@139.com
}

Genet. Mol. Res. 16 (2): gmr16027940

Received October 28, 2016

Accepted November 30, 2016

Published June 29, 2017

DOI http://dx.doi.org/10.4238/gmr16027940

Copyright (C) 2017 The Authors. This is an open-access article distributed under the terms of the Creative Commons Attribution ShareAlike (CC BY-SA) 4.0 License.

\begin{abstract}
Acid and pepsin-soluble collagen (ASC and PSC, respectively) were extracted from cod (Gadus macrocephaius) skin, and yields of 37.36 and $55.96 \%$ were obtained for ASC and PSC, respectively. The total yield of ASC and PSC was $93.92 \%$, based on the lyophilized dry weight, which is higher than that obtained from other sources. Electrophoresis revealed that both ASC and PSC consisted of two different $\alpha$-chains ( $\alpha 1$ and $\alpha 2$ ), which were characterized as type I collagen. Analysis of amino acids showed that both the ASC and PSC contained imino acids (216.1 and 190.6 residues/1000 residues, respectively) and the Fourier transform infrared spectroscopy spectra of both collagens were similar with pepsin hydrolysis having no effect on their triple-helical structure. The thermal denaturation temperature of ASC and PSC, as measured by viscometry, was $26.8^{\circ}$ and $25.6^{\circ} \mathrm{C}$, respectively.
\end{abstract}

Key words: Collagen; Physical-chemical characteristics

Genetics and Molecular Research 16 (2): gmr16027940 


\section{INTRODUCTION}

Collagen is the most abundant protein in vertebrates, and it constitutes approximately $30 \%$ of their total protein. There are at least 27 different types of collagen, which are named type I-XXVII. Type I collagen is commonly found in connective tissues, including tendons, bones, and skin. All members of the collagen family are characterized by domains containing repeats of proline-rich tripeptides, Gly-X-Y, which are involved in the formation of the collagen triple helix. Collagen has a wide range of applications in the leather and film industries, in cosmetic and biomedical materials, and in the food industry.

Following outbreaks of bovine spongiform encephalopathy, transmissible spongiform encephalopathy, and foot-and-mouth disease, the use of collagen and collagen-derived products from land animals has been met with concern. Additionally, collagen obtained from pig skin and bones cannot be used freely owing to religious constraints. As a consequence, considerable attention has been paid to alternative sources of collagen, especially that extracted from fish skin and bones derived from seafood processing industries. Thus far, collagen from the skin of several fish species, including bigeye snapper (Jongjareonrak et al., 2005), Baltic cod, and deep-sea redfish (Wang et al., 2007) has been isolated and characterized. However, the methods used to isolate collagen from cattle skin are not effective at isolating collagen from fish skin. The collagen yield and amino acids were selected as indices to compare the characteristics of ASC (Acid pepsin-soluble collagen) and PSC (pepsin-soluble collagen) extracted from cod skin.

\section{MATERIAL AND METHODS}

\section{Materials}

Several cod (Gadous macrocephaius) were purchased from Qinhuangdao, China. After the cod were sacrificed, the skins were removed, descaled, and washed with distilled water. The cleaned skins were cut into small pieces (less than $5 \mathrm{~mm}$ ), thoroughly mixed, and the prepared samples were then stored at $-20^{\circ} \mathrm{C}$ in polyethylene bags.

\section{Chemicals/enzymes}

Sodium chloride and sodium hydroxide were purchased from Tianjin Kemiou Chemical Reagent Co., (Tianjin, China), standards for type I collagen and pepsin were purchased from Sigma-Aldrich (Beijing, China). All other chemicals and reagents used were of analytical grade.

\section{Removal of non-collagenous proteins and fat from cod skin}

Skin samples were treated with $0.02 \mathrm{M} \mathrm{NaOH}$ (7.5\% sodium chloride solution) at a ratio of $1: 10(\mathrm{w} / \mathrm{v})$ to remove non-collagenous proteins, and mixtures were continuously stirred for $18 \mathrm{~h}$. Next, the deproteinized skin was washed with distilled water until the water reached a neutral or weakly basic $\mathrm{pH}$.

\section{Extraction of ASC}

All processes were carried out at $4^{\circ} \mathrm{C}$ with continuous stirring. The pretreated skins

Genetics and Molecular Research 16 (2): gmr16027940 
were defatted with $10 \%$ butyl alcohol at a solid/solvent ratio of $1: 10(\mathrm{w} / \mathrm{v})$ for $48 \mathrm{~h}$, with the solvent being changed every $8 \mathrm{~h}$. Defatted skin was washed with cold water $\left(5^{\circ}-8^{\circ} \mathrm{C}\right)$ and then soaked in $0.47 \mathrm{M}$ acetic acid at a solid/solvent ratio of $1: 33(\mathrm{w} / \mathrm{v})$ for $90.2 \mathrm{~h}$. The resultant precipitate was collected by centrifugation at $10,000 \mathrm{rpm}$ for $20 \mathrm{~min}$ at $4^{\circ} \mathrm{C}$. The pellet was dissolved in a minimum volume of $1 \mathrm{M} \mathrm{NaCl}$ which contain $0.05 \mathrm{M}$ Tris- $\mathrm{HCl}(\mathrm{pH}$ 7.4) for 12 $\mathrm{h}$. The collagen was precipitated by adding $\mathrm{NaCl}$ solution to a final concentration of $2.5 \mathrm{M}$ for 12 then centrifuging at $11,180 \mathrm{~g}$ for $20 \mathrm{~min}$ at $4{ }^{\circ} \mathrm{C}$. The resultant precipitate was dissolved in a minimum volume of $0.5 \mathrm{M}$ acetic acid for $12 \mathrm{~h}$, followed by dialysis in the same volume of distilled water at $10,000 \mathrm{rpm}$ for $20 \mathrm{~min}$ at $4^{\circ} \mathrm{C}$. Then the resultant precipitate was redissolved in a minimum volume of $0.5 \mathrm{M}$ acetic acid and was stirred and then subjected to dialysis in the same volume of $0.5 \mathrm{M}, 0.1 \mathrm{M}$ acetic acid and distilled water respectively. The dialysate was freeze-dried and thereafter referred to as ASC. The ASC yield was calculated from the difference in the percentage dry-weight of collagen extracted and the wet weight of the initial skin sample used.

\section{Extraction of PSC}

Pretreated skin was dissolved using a solid/solvent ratio of $1: 31(\mathrm{w} / \mathrm{v})$ for $17.6 \mathrm{~h}$ in the presence of pepsin (850 unit/g defatted skins). The filtered liquid was collected by centrifugation at $10,000 \mathrm{rpm}$ for $30 \mathrm{~min}$ at $4^{\circ} \mathrm{C}$. Collagen was precipitated by adding $\mathrm{NaCl}$ solution to a final concentration of $0.9 \mathrm{M}$ for $12 \mathrm{~h}$ and centrifuging at 10,000 rpm for $20 \mathrm{~min}$ at $4{ }^{\circ} \mathrm{C}$. The resultant precipitate was dissolved in a minimum volume of $0.05 \mathrm{M}$ Tris- $\mathrm{HCl}(\mathrm{pH}$ 7.4) acetic acid for $12 \mathrm{~h}$, and then dialyzed in the same volume of distilled water for 10,000 $\mathrm{rpm}$ for $20 \mathrm{~min}$ at $4^{\circ} \mathrm{C}$. The filtrate was subjected to precipitation and the pellet was dialyzed in the same manner as the ASC samples as previously described. The dialysate was freeze-dried and thereafter referred to as the PSC. The yield of PSC was calculated in the same manner as that of the ASC. Additionally, the collagen yield was calculated on the basis of the yield of ASC and PSC.

\section{Determination of proximate compositions}

The cod skins were determined after blended. Moisture, crude fat, ash, and crude protein levels in skin were determined according to the Association of Official Analytical Chemists methods.

\section{Analysis of amino acidsi}

The sample were hydrolyzed under decompression in $4 \mathrm{M}$ methane sulphonic acid containing $0.2 \%(\mathrm{v} / \mathrm{v}) 3-2\left(2\right.$-aminoethyl) indole at $115^{\circ} \mathrm{C}$ for $24 \mathrm{~h}$. The hydrolysates were neutralized with $3.5 \mathrm{M} \mathrm{NaOH}$ and diluted in $0.2 \mathrm{M}$ citrate buffer (pH 2.2). A 0.4-mL aliquot was analyzed by high-performance liquid chromatography.

\section{SDS-polyacrylamide gel electrophoresis (SDS-PAGE)}

Samples were dissolved in $5 \%$ SDS and the mixtures were incubated at $85^{\circ} \mathrm{C}$ for $1 \mathrm{~h}$ in a water bath. The mixture was centrifuged at $10,000 \mathrm{rpm}$ for $5 \mathrm{~min}$ at room temperature to

Genetics and Molecular Research 16 (2): gmr16027940 
remove undissolved debris. Solubilized samples were mixed at a ratio of $1: 1(\mathrm{v} / \mathrm{v})$ with the sample buffer ( $0.5 \mathrm{M}$ Tris- $\mathrm{HCl}$, pH 6.8, containing 4\% SDS and 20\% glycerol) containing $10 \%$ $\beta$-ME. The mixtures were incubated in boiling water for $2 \mathrm{~min}$. Samples ( $15 \mu \mathrm{g}$ protein) were loaded onto polyacrylamide gels comprising a $7.5 \%$ running gel and a $4 \%$ stacking gel, and subjected to electrophoresis at a constant current of $15 \mathrm{~mA} / \mathrm{gel}$ for $1.5 \mathrm{~h}$. After electrophoresis, the gel was stained with $0.05 \%$ Coomassie blue R-250 (w/v) dissolved in 15\% methanol (v/v) and $5 \%$ acetic acid $(\mathrm{v} / \mathrm{v})$, and destained with $30 \%$ methanol $(\mathrm{v} / \mathrm{v})$ and $10 \%$ acetic acid $(\mathrm{v} / \mathrm{v})$. High-molecular weight markers were used to estimate the molecular weight of proteins. The markers used included myosin (200 kDa), $\alpha 2$-macroglobulin $(170 \mathrm{kDa}), \beta$-galactosidase (116 $\mathrm{kDa})$, transferrin $(76 \mathrm{kDa})$, and glutamate dehydrogenase (53 kDa). Type I collagen from calf skin was used as a standard.

\section{Attenuated total reflectance-Fourier transform infrared spectroscopy (ATR-FTIR) analysis}

Both ASC and PSC were subjected to ATR-FTIR. A FTIR spectrometer equipped with a horizontal ATR trough plate crystal cell (45_ZnSe; $80 \mathrm{~mm}$ long, $10 \mathrm{~mm}$ wide, and 4 $\mathrm{mm}$ thick) was used. For spectrum analysis, the collagen samples were placed onto the crystal cell, which was then clamped into the mount of the FTIR spectrometer. Spectra in the range of 400-5000 $\mathrm{cm}^{-1}$ with an automatic signal gain were collected in 32 scans at a resolution of 4 $\mathrm{cm}^{-1}$ and were ratioed against a background spectrum recorded from the empty cell at $25^{\circ} \mathrm{C}$.

\section{Determination of denaturation temperature}

The denaturation temperature was determined using a Rheometer (CN66M233256, Kesijia Technology, China). Viscosity was measured using $10-\mathrm{mL}$ samples of $0.03 \%$ collagen in $0.1 \mathrm{M}$ acetic acid- $0.2 \mathrm{M}$ sodium acetate buffer. A thermal determination curve was obtained from $7^{\circ}$ to $41^{\circ} \mathrm{C}$ and the designated temperature was raised stepwise and maintained for 20 $\mathrm{min}$. The measurement was carried out three times at each point. Next, the fractional viscosity at a given temperature was calculated using the following equation: fractional viscosity $=$ (maximum viscosity - measured viscosity) / (maximum viscosity - minimum viscosity). These fractional viscosities were plotted against temperature, and the denaturation temperature was taken to be the point at which the fractional viscosity was 0.5 .

\section{RESULTS}

\section{Proximate composition of cod skin}

Analysis of the proximate composition of cod skin revealed that the moisture content on a dry-weight basis was $10.84 \%$. The crude protein, crude lipid, and ash content of cod skin on a dry-weight basis were $82.06,2.60$, and $2.30 \%$, respectively.

\section{Amino acid composition of ASC and PSC}

The amino acid compositions of ASC and PSC, expressed as residues per 1000 total amino acid residues (residues/1000 residues), are shown in Table 1. The ASC and PSC extracted 
from cod skin revealed similar amino acid profiles. The levels of imino acids (proline and hydroxyproline) are important for the structural integrity of collagen. The imino acid content of ASC and PSC extracted from cod skin was 216.1 and 190.6 residues/1000 residues, respectively.

Table 1. Amino acid composition of ASC and PSC from cod skin (residues/1000 residues).

\begin{tabular}{l|c|c}
\hline Amino acid & ASC & PSC \\
\hline Aspartic acid & 34.9 & 26 \\
\hline Glutamic acid & 49.6 & 8.9 \\
\hline Histidine & 7.3 & 41.4 \\
\hline Serine & 40.2 & 43.8 \\
\hline Arginine & 46.7 & 350.1 \\
\hline Glycine & 342.3 & 5.4 \\
\hline Threonine & 18.8 & 142.6 \\
\hline Taurine & 2 & 37.8 \\
\hline Alanine & 138.2 & 2 \\
\hline Valine & 37.4 & 1.6 \\
\hline Methionine & 4.5 & 12.2 \\
\hline Cystine & 1.4 & 20.1 \\
\hline Isoleucine & 10.2 & 1.5 \\
\hline Leucine & 10.8 & 20.6 \\
\hline Tryptophan & 1.2 & 9.2 \\
\hline Phenyalanine & 18.8 & 9.2 \\
\hline Lysine & 13.6 & 114.4 \\
\hline P-hydroxyphenylalanine & 6 & 76.2 \\
\hline Proline & 125.6 & 1000 \\
\hline Hydroxyproline & 90.5 & 190.6 \\
\hline Total & 1000 & \\
\hline Imino acid & 216.1 & \\
\hline
\end{tabular}

\section{SDS-PAGE of ASC and PSC from cod skin}

Figure 1 shows both the ASC and PSC consisted of $\alpha$-chains ( $\alpha 1$ and $\alpha 2)$ and their dimers $(\beta)$. The patterns were similar to that of type I collagen from calf skin (Figure 1). However, for both collagens, the band intensity of the $\alpha 1$-chain was not double that of the $\alpha 2$-chain. A small amount of this kind of dimer and trimer was observed in the ASC of cod. High-molecular weight components were observed in the ASC, including $\beta$ and $\gamma$ collagen. Two $\alpha$-chains of PSC were visibly present at higher levels than those of ASC.

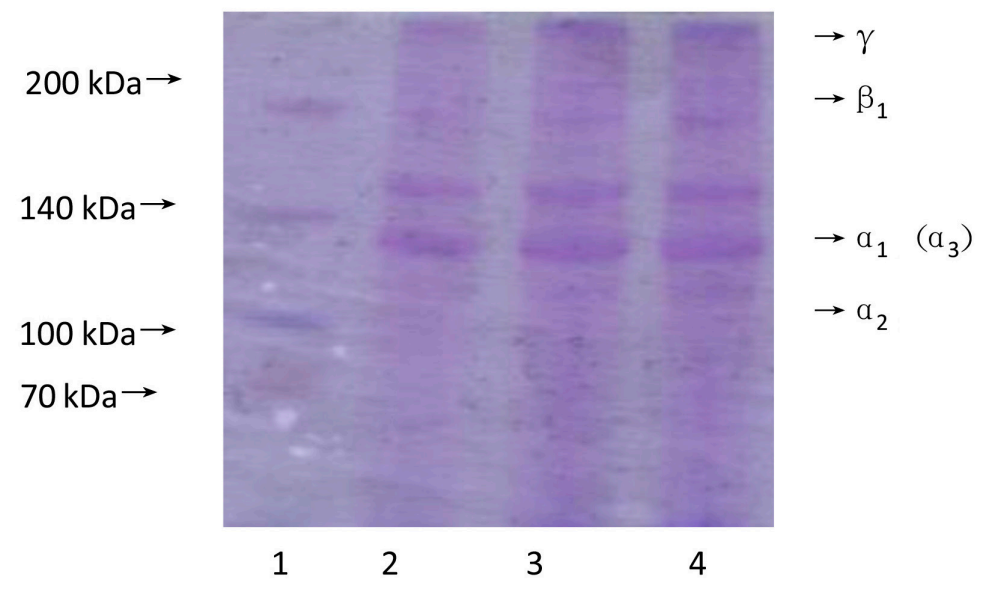

Figure 1. SDS-PAGE profile of cod skin collagen. 


\section{FTIR spectroscopy spectra of ASC and PSC from cod skin}

The FTIR spectra of ASC and PSC extracted from cod skin are shown in Figure 2. The major peaks in the spectra of both ASC and PSC from cod skin were similar to those of collagen from others fish species. Similar FTIR spectra were observed between ASC and PSC. The amide A bands of ASC and PSC were found at 3307 and $3305 \mathrm{~cm}^{-1}$, respectively. This band is generally associated with the $\mathrm{N}-\mathrm{H}$ stretching vibration and reveals the existence of hydrogen bonds. When the NH group of a peptide is involved in a hydrogen bond, the position is shifted to a lower frequency. The amide B band of both collagens was observed at 3068-3077 $\mathrm{cm}^{-1}$. The amide I band of ASC and PSC were observed at 1650 and 1646 $\mathrm{cm}^{-1}$, respectively. This band is associated with $\mathrm{C}=\mathrm{O}$ stretching vibration or with a hydrogen bond coupled with $\mathrm{COO}^{-}$. This was confirmed by the ratio of the amide III and $1454 \mathrm{~cm}^{-1}$ bands in both collagens being approximate to 1. Thus, both ASC and PSC showed a similar secondary structure.

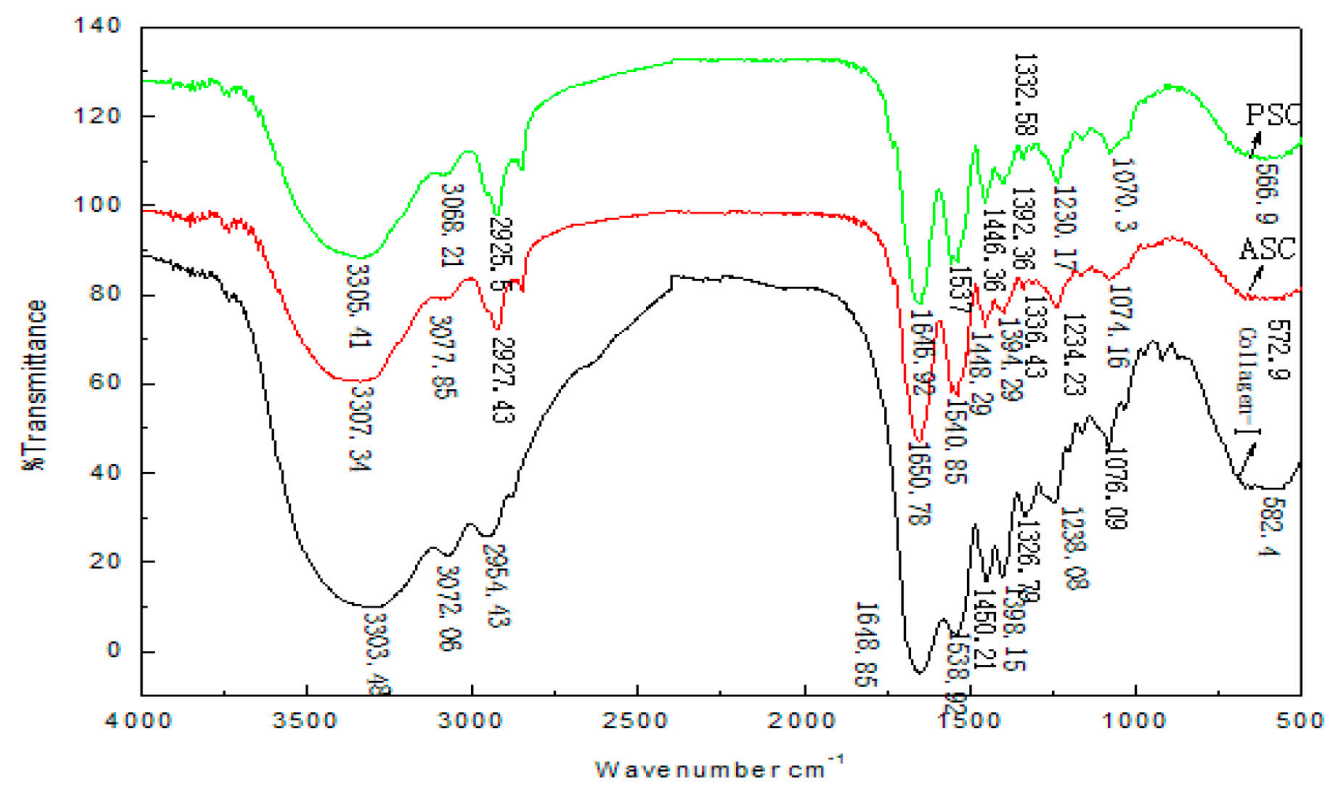

Figure 2. FTIR spectroscopy spectra peak of ASC and PSC from cod skin and standard type-I collagen.

\section{Denaturation temperature of the ASC and PSC}

Figure 3 shows the changes in fractional viscosity with increasing temperature. The denaturation temperatures of ASC and PSC extracted from cod skin were calculated to be $26.8^{\circ}$ and $25.6^{\circ} \mathrm{C}$, respectively. There was no difference between the ASC and PSC as determined by the viscosity measurements, indicating that pepsin digestion may not affect the collagen structure, particularly, the triple-helical structure.

Genetics and Molecular Research 16 (2): gmr16027940 


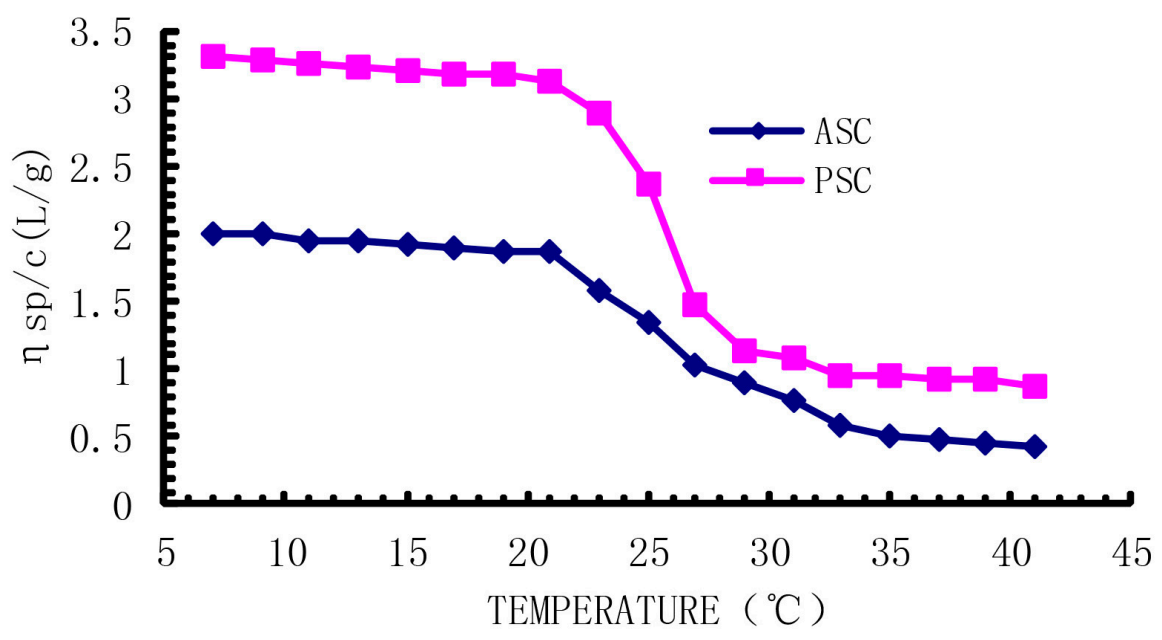

Figure 3. Thermal denaturation curve of ASC and PSC from cod skin.

\section{DISCUSSION}

These results showed that the contents of ASC and PSC extracted from cod skin were significantly higher than those from the skin of land animals. There are three reasons to explain this difference. First, there are significantly higher levels of protein and significantly lower levels of fat in cod than in land animals. Additionally, the collagen obtained from cod skin can be used freely. Second, the ASC and PSC extracted from cod skin had similar amino acid profiles. The imino acid content of the collagen was higher than that of edible jellyfish, dusky spinefoot, cod, ocellate puffer, and bullfrog, which have been found to contain imino acids ranging from 180 to 216 residues/1000 residues. The present results support the finding that differences in the imino acid content in animals are associated with differences in their habitats (Love et al., 1976). The pyrrolidine rings of proline and hydroxyproline impose restrictions on the conformation of a polypeptide chain and help to strengthen the triple helix. Furthermore, the imino acid content contributes to the thermal stability of the helical structure of collagen, owing to the fact that the Hydroxyproline rich zones of the molecules are most likely to be involved in the formation of junctions that are stabilized by binding to hydrogen. In general, glycin is major amino acid and represent one-third of the total amino acid residues in collagen. This is because glycine could be found at every third residue throughout the central region of the $\alpha$-chain, with the exception of the first 14 amino acid residues from the $\mathrm{N}$-terminus and the first 10 amino acid residues from the $\mathrm{C}$-terminus of the collagens.

Third, the major constituents of both the ASC and PSC, $\alpha$-chains ( $\alpha 1$ and $\alpha 2)$ and their dimers $(\beta)$, were similar to those of type I collagen from calf skin (lane 1 ) and the skin of most other fish species. ASC and PSC extracted from the skin of balloon fish showed that the use of pepsin could aid in obtaining a greater yield without having a noticeable effect on the triple-helical structure. Cod skin collagens consisted of two $\alpha$-chains $(\alpha 1$ and $\alpha 2)$ and were classified as type I, as they lack a disulfide bond.

Finally, the denaturation temperatures of the ASC and PSC were approximately $26.8^{\circ}$ and $25.6^{\circ} \mathrm{C}$, respectively. These results suggest that cod skin has potential as an alternative source of collagen for use in various fields.

Genetics and Molecular Research 16 (2): gmr16027940 


\section{Conflicts of interest}

The authors declare no conflict of interest.

\section{REFERENCES}

Jongjareonrak A, Benjakul S, Visessanguan W and Tanaka M (2005). Isolation and characterisation of collagen from bigeye snapper (Priacanthus marcracanthus) skin. J. Sci. Food Agric. 85: 1203-1210. http://dx.doi.org/10.1002/jsfa.2072

Love RM, Yamaguchi K, Créac'h Y and Lavéty J (1976). The connective tissues and collagens of cod during starvation. Comp. Biochem. Physiol. B 55: 487-492. http://dx.doi.org/10.1016/0305-0491(76)90005-5

Wang L, An X, Xin Z, Zhao L, et al. (2007). Isolation and characterization of collagen from the skin of deep-sea redfish (Sebastes mentella). J. Food Sci. 72: E450-E455. PubMed http://dx.doi.org/10.1111/j.1p750-3841.2007.00478.x 